\title{
RICE BRAN: AN NATURAL ANTIOXIDANT AND ITS HEALTH BENEFITS
}

\section{JHA S AND ROY P}

Amity Institute of Biotechnology, Amity University, Gautam Buddha Nagar, Sector-125, Noida, Uttar Pradesh, India

*Corresponding Author: Dr. Shipra Jha; E Mail: sjanvi79@gmail.com

Received $8^{\text {th }}$ March 2021; Revised $6^{\text {th }}$ April 2021; Accepted $6^{\text {th }}$ May 2021; Available online $1^{\text {st }}$ Jan. 2022

https://doi.org/10.31032/IJBPAS/2022/11.1.5813

ABSTRACT

Dietary antioxidants protect the body against free radical production due to oxidation reactions inside the body and protect from their damaging effects. Free radical biology and antioxidant property of prevention have emerging research interests. Rice bran oil (RBO) has natural antioxidant components having antioxidant properties due to the presence of bioactive phytochemicals. The bioactive components such as oryzanol, alpha-tocopherol, tocotrienols of rice bran have been reported for exhibiting antioxidant, anti-inflammatory, anti-allergic, cholesterol-lowering properties, anti-cancer, and antidiabetic properties. Rice bran has extraordinary properties with high oxygen radical absorbance capacity (ORAC) value as compared to other vegetable oils. This report aims to discuss the nutritional and phytochemical components of RBO and their mechanism of action in preventing and management of various chronic diseases. As part of this study, a survey was also conducted on the mixed population to analyze how the deficiency of antioxidants is linked to dietary habits, income, age group, various lifestyle-related disorders, and public awareness regarding antioxidants.

\section{Keywords: Rice bran, Bran oil, RBO, Antioxidant, Oryzanol, Vitamin E, Phytochemicals}

\subsection{INTRODUCTION}

Recent development in medical field report that chronic diseases associated with the free radicals due oxidative stress caused by bad lifestyles \& acquaintance of chemicals, pollution, smoking, alcohol, illness, anxiety, stress etc. and dietary habits of people. Exogenous consumption of natural antioxidants (vit $\mathrm{C}$, vit $\mathrm{E}$, polyphenols, beta 
carotenoids, flavonoids, vit A) can be beneficial for human health and wellness [1-5]. Rice bran is the nutritiously valuable part of the rice crop. The outer surface layer of rice bran is the hard consist of the aleurone \& pericarp. During milling process of rice, consist of the endosperm $(70 \%)$ white portion that we usually consume, rice husk $(20 \%)$, rice bran $(8 \%)$ a hard outer covering of rice and rice germ layer $(2 \%)$ get as the by-product. when rough rice is milled, it will have converted into polished white edible grain. In simple word the brown covering of rice is removed [1-5]. This process generates wastage from milling process called Rice bran. The nutritional value of rice lies in the bran and germ which was discarded during the milling process in the past times [6-9].

In early times it was discarded due to its rancid smell and people are not fully aware of its uses. Rancidity problem is related to the process of oxidation of fats and oil present in rice which can be noticed by change in the taste [10-11]. Lipase enzyme is the major cause of the rancidity which is produced during milling process which makes the bran unsuitable for consumption and bitter in taste. Due to the reason previously rice bran was underutilized. To prevent rancidity of rice bran, there are several methods are invented to inhibit the lipase enzyme action for the stabilization of the most suitable method to overcome the stabilization problem of $\mathrm{RB}$ is "'ohmic heating', which reduces the adverse effect of oxidation on oil quality [12-13].

There is developing attention in the use of naturally occurring antioxidants for the administration of a numeral of pathophysiological circumstances involving the protection from free radical damage [14-16]. Eating exogenous antioxidants forms one of the resistance mechanisms that protects the body against the damaging effects of reactive oxygen species (ROS). Among these antioxidant constituents, rice bran oil is a great source of gamma oryzanol. Recent exploration on rice antioxidants has recognized that rice bran, the external layer of rice scrap is rich source of gamma oryzanol and Vitamin E include tocopherols \& tocotrienols which show significant antioxidant activity.At present researchers are conducted to utilized native rice bran for oil extraction as well as for preparation of value added products in pharmaceutical industries [17].

\section{REVIEW OF LITERATURE}

Rice bran has antioxidant property.The natural endogenous antioxidants are produced by the body to make free radicals protect and protect the body from various diseases. The antioxidant defense systems can be divided into two groups of enzymatic and enzymatic antioxidants. The antioxidants that are given out through our diet are called external antioxidants. 
Antioxidants in our diet can convert excessive free radicals and help endogenous antioxidants. Vit C, Vit E, carotenoids, beta carotene, flavonoids etc. it is used as a food and nutritional enhancement for Exo native antioxidants from natural sources [.Geno are divided into various groups: vitamins, polyphenols, minerals, Carotenequality [18-19].

It has greater potential applications in food industries due its nutritional values, greater fry stability and longer shelf life and have good ORAC value [20]. Various research studies about the Rice bran as a natural antioxidant component are undertaking concern about the effects of rice bran consumption due to its high nutritional value and dietary antioxidant properties [21-23]. It has high pharmaceutical and therapeutic application by preventing disease with no side effects. Some studies concluding that rice bran consumption has the capacity to control CVD disease 1, cholesterol lowering, and the potential to have a noteworthy impact on cancer, ocular disorders, menopausal syndrome, obesity, hypothyroidism, hyperthyroidism and neurodegenerative disorders (Table 1). The mostly used product of rice bran is its Rice Bran oil that with brilliant properties as compared to other edible oils [24-27].

Table 1: Health benefits of Rice Bran

\begin{tabular}{|c|c|c|}
\hline \multicolumn{3}{|c|}{ Health benefits of Rice Bran } \\
\hline Properties & Active components and benefits & Reference \\
\hline Antioxidants & $\begin{array}{c}\text { Conjugation of Gamma Oryzanol,tocols and phytosterol } \\
\text { have property against the free radicals }\end{array}$ & Zhua 2009[28] \\
\hline $\begin{array}{c}\text { Coronary Heart } \\
\text { disease }\end{array}$ & $\begin{array}{c}\text { Presence of 10\% of total dietary fiber, phytosterols, } \\
\text { tocotrienols, triterpene alcohols and tocopherols in rice } \\
\text { bran oil acts as hypochlesterolemic agent }\end{array}$ & $\begin{array}{c}\text { Saguno 1997;Wilson } \\
2000[29-30]\end{array}$ \\
\hline Colorectal cancer & $\begin{array}{c}\text { Rice bran contains tricin, } \boldsymbol{\beta} \text {-sitosterol,tocotrienols, } \gamma \text { - } \\
\text { oryzanol,phytic acid and ferulin components shows } \\
\text { chemopreventive property }\end{array}$ & $\begin{array}{c}\text { Verschoyle 2007; Barnes } \\
1983 \\
{[31-32]}\end{array}$ \\
\hline $\begin{array}{c}\text { Diabetes Milletus } \\
\text { Lowering } \\
\text { cholesterol }\end{array}$ & $\begin{array}{c}\text { Presence of lipolic acid in bran oil can prevent } \\
\text { neuropathy,retinopathy }\end{array}$ & $\begin{array}{c}\text { Qureshi et.al.2002[33] } \\
\text { Helps in treatment of Alzheimer's disease }\end{array}$ \\
\hline Anti-aging & $\begin{array}{c}\text { High concentration of phytosterols, tocotrienols and } \\
\text { which results in reduction of LDL and cholesterol }\end{array}$ & $\begin{array}{c}\text { Lichtenstein et.al } \\
1994 ; \text { Hegsted 1993[34-35] }\end{array}$ \\
\hline $\begin{array}{c}\text { Post-menopausal } \\
\text { syndrome }\end{array}$ & $\begin{array}{c}\text { Oryzanol can be used as sunscreen agent } \\
\text { Genopausal symptoms and reduction of overscretion of } \\
\text { FSH and LH }\end{array}$ & $\begin{array}{c}\text { Nobor 1970;Eitenmiller } \\
1997[36-37]\end{array}$ \\
\hline
\end{tabular}

\subsection{METHODOLOGY}

\subsection{Research Approach}

A survey based approach was carried out in order to get an idea about the various life style related disorders due to lack of intake of proper antioxidant rich diet and to knowthe awareness of the population about the health benefit of Rice Bran oil over other edible oils with high preference.

\subsection{Sampling and Data Collection}

In the present study, random sampling method was adopted and a questionnaire 
was used for the data collection. The survey was conducted during the month of March May, 2020 through a questionnaire which was designed to gain a more detailed understanding about the consumer's awareness and opinions towards the Rice Bran oil.

The total number of people (respondents) put to conduct research for this survey was 108. Both male and female respondents were included in the survey and they were between age group 18-50 years

\subsection{Questionnaire and Measures}

The Questionnaire was structured with a combination of demographic and conceptual factors. Both open ended and closed questions as well as qualitative and quantitative questions were used depending on the situation. Short questions were encouraged as they are usually more effective than longer ones. The first part of the questionnaire was aimed at assessing the respondent's gender, age and residence to find demographic factors about the respondents.

The questions included in the second section were aimed at assessing the respondents' dietary habits, awareness and preference about antioxidant rich diet and edible oil consumption. The survey forms were made online by using Google forms application that was circulated to mixed population through E mail, WhatsApp and Facebook.
Finally, a few questions were asked to get an idea about the respondent's choice of edible oil, where respondents were asked to assign the level of importance of different categories such as price, nutritional value, health benefits obtained from the preferred edible oil generally. The response categories were; "very important (5)", "important (4)", "moderately important (3)", "little important (2)" and "unimportant (1)". In addition to that, questions about the preferred type, price, and flavor of edible oil were included to get an idea of the consumer's preference on edible oils.

Finally, the consumers' preference was asked in order to check whether they would like to prefer Rice Bran oil over other available edible oils considering its health benefits.

\subsection{Data Analysis}

The data collected from the research were analyzed by Chi square test based pie chart. The pie chart was used to analyzethe data bycomparing variables. During testing parametric and non-parametric test was conducted.

\section{RESULTS AND DISCUSSION}

A consumer's dietary behavior is governed by several limitless factors which includes, physical and social environment, their approach towardthe product. Hence, studying variables with respect to Rice Bran oil is consider to be most important 
and it will help to maximize the usage so that the whole community is benefitted from its health benefits.

\subsection{Descriptive Analysis}

According to data collected, there are $(10.2 \%)$ of cigarette smokers and $39.8 \%$ of people are not involved in any kind of physical work. Cigarette smoke generate high level of Reactive oxygen species or free radicals. Researchers reported that the smokers group have low level of antioxidants in plasma due to greater utilization of endogenous antioxidant present inside body defense system against Free radicals. Smokers are advice to take diet rich in antioxidant foods. Few of them are suffering from various diseases cardiovascular, cancer, rheumatoid arthritis, menopause syndrome, gastrointestinal diseases, eye disorder, dengue, migraine, hypothyroid. Majority of them have weak eye sight (44.4\%) \& (41.7\%) facing stress or anxiety. Researchers suggest that higher ingestion of beta carotene (vit A) \& vit C have excellent role in vision and eye related disorders related to oxidative stress. Sources include green vegetables yellow fruits (papaya, mango). There are many nutritious components of RBO and their beneficial health are found. RBO has an unconfigurable extractions, which contains phytochemicals such as vit E, gammaoryzanol, phytosterols, polyphenols (Table
Respondent responses to question related to awareness about antioxidant, 67.6\% know the term antioxidant but majority of people (64.8\%) people are unaware about the health benefits of antioxidants.

Respondent response to question related to every day dietary habits. There are majority of non-vegetarian (57.4\%) compared to (37\%) vegetarian. According to ORAC value fresh fruits and vegetables have high amount of antioxidant capacity compares to the non-vegetarian diet include meat, fish. Only $35.2 \%$ of people consuming fresh fruits daily, $32.4 \%$ consume twice in a week, $23.1 \%$ once in a week which conclude that recent population are not consuming sufficient amount of antioxidant rich fruits having high ORAC value. 33.3 $\%$ of people are not consuming citrus fruits juices. Class of vitamin $\mathrm{C}$ containing citrus fruits: orange, berry lemon etc. have high ORAC value among fresh fruits. Only $53.7 \%$ of population consuming green vegetable \& 46.3\% are not consuming vegetables. Green vegetable, nuts, walnuts are rich source of vitamin $E$ antioxidant.35.2 \% of population is not consuming tea, only $26.9 \%$ consume 1 cup per day, $28.7 \% 2$ cups per day and $9.3 \% 3$ por more cups per day, green tea is ironic source of flavonoids specially catechins with high ORAC value $(1253 \mu \mathrm{mol}$ TE/100g) (Table 3, Figure 2a, 2b, 2c).

2, Figure 1a, 1b). 
Table 2: Data related to social life style \& medical history of respondent

\begin{tabular}{|c|c|c|}
\hline Question asked & Responses (no. \& \%) & No \\
\hline & Yes & $\mathbf{9 7 ( 8 9 . 8 \% )}$ \\
\hline 1. Smoking habit & $\mathbf{1 1 ( 1 0 . 2 \% )}$ & $\mathbf{1 0 5 ( 9 7 . 5 \% )}$ \\
\hline 2. Alcoholic & $\mathbf{3 ( 2 . 8 \% )}$ & $\mathbf{4 3 ( 3 9 . 8 \% )}$ \\
\hline 3. Physical work or exercise & $\mathbf{6 5 ( 6 0 . 2 \% )}$ & $\mathbf{6 0 ( 5 5 . 6 \% )}$ \\
\hline 4. Weak eye sight & $\mathbf{4 8 ( 4 4 . 4 \% )}$ & $\mathbf{5 5 ( 5 8 . 3 \% )}$ \\
\hline
\end{tabular}

108 responses

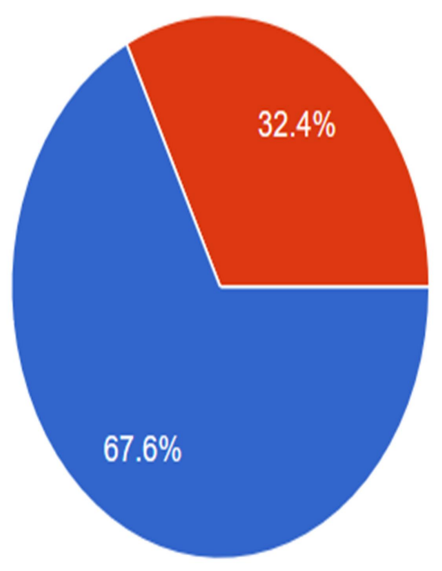

Figure 1 (a): Pie Charts represents public awareness about antioxidants

108 responses

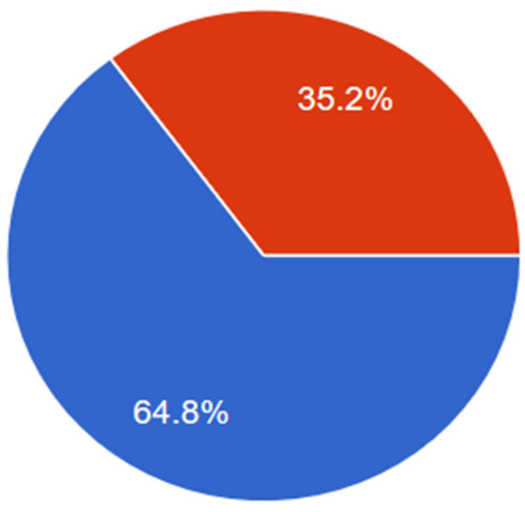

Figure 1 (b): Pie chart represents public awareness about RB health benefits 
Table 3: Dietary habits of people

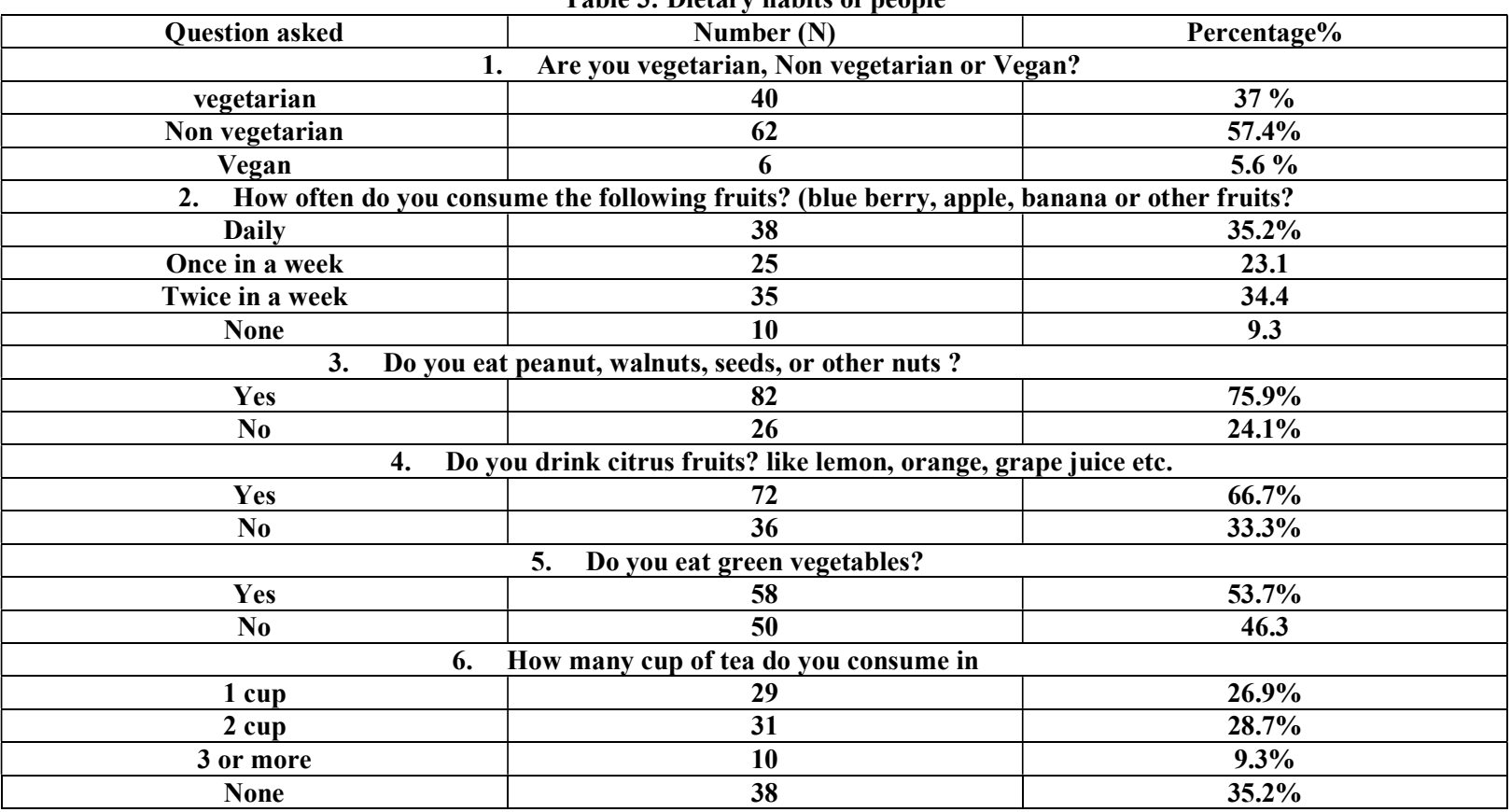

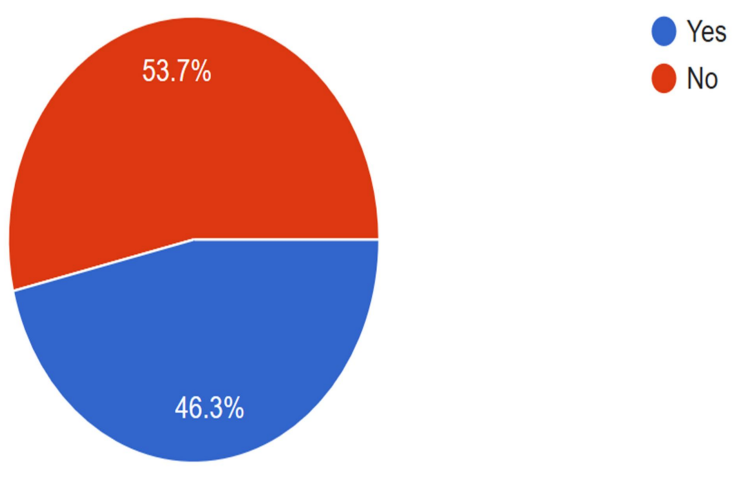

(a) 
108 responses

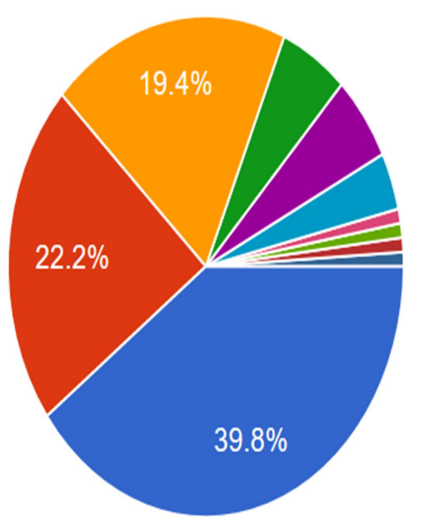

sunflower
mustad
soyabean
groundnut
rice bran
Olive oil
Sarso
olive
$1 / 2$

(b)

108 responses

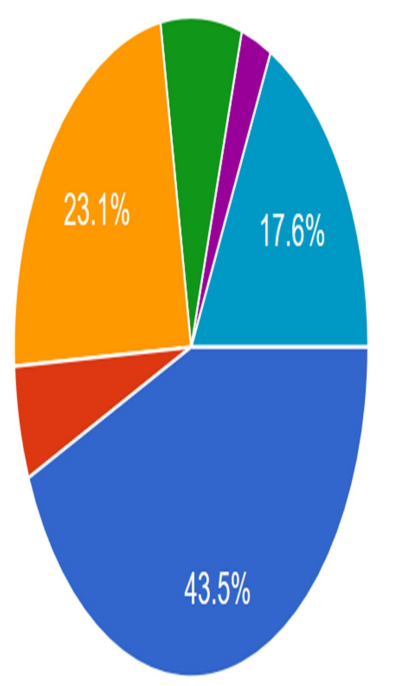
quality
oprice
past experience
brand
offer and scheme
health benifits

(c)

Figure 2: Pie charts indicating - (a) Awareness about RB oil (b)Types of edible oils used for daily consumption (c) Consumer preference for quality determination of edible oil 
According to the result received, People are using many different varieties of edible oil like majority of them are consuming sunflower oil $39.8 \%$, mustard oil $22.2 \%$, soyabean oil $19.4 \%$, ground oil (5.6\%), rice bran 5.6\%. among these oils. Majority of people $(53.7 \%)$ are not aware of rice bran oil and $69.8 \%$ of people are not known to the health beneficial property of rice bran. Rice bran oil with "ideal" SFA/MUFA/PUFA ratio in comparison to other edible oils and have a unique anticholesterolemic lowering property which lowers the blood cholesterol.

The result obtained based on the survey conducted on the dietary habits and awareness among respondent about antioxidants. It was found that the people are not fully aware about the role of antioxidant hence they are not consuming sufficient amount of dietary antioxidant in every day diet.

\section{CONCLUSION}

Rice bran oil is considered to be a healthy alternative to the people who are not consuming sufficient amount of exogenous antioxidant from their diet. Due to low income status they are unable to get antioxidant fruits and vegetable daily. Therefore, they can replace it by consuming natural antioxidant rich Rice bran oil by replace it with their daily edible oils so they can get daily antioxidants through RBO consumption to fight against the free radical species which effects their immune system. Rice bran is good source natural antioxidant i.e. Oryzanol and Vitamin E. it is easy available in market at affordable price. Therefore, it's important for food industries to enhance the nutraceutical components in rice bran by introducing new techniques to enrich and alleviate lifestyle disease.

\section{REFERENCES}

[1] Agudo A, Slimani N, Ocke MC, Naska A, Miller AB, et al. (2002) Consumption of vegetables, fruit and other plant foods in the European Prospective Investigation into Cancer and Nutrition (EPIC) cohorts from 10 European countries. Publ Health Nutr, 5: $1179-1196$

[2] Wadsworth JI Rice. In: Hui Y H, ed. Encyclopedia of Food Science \& Technology, 4th ed. New York, Pa: John Wiley \& sons 1992; 264279.

[3] Wells JH (1993) Utilization of rice bran \& oil in human diets. Louisiana Agriculture, 36: 4-8.

[4] Xu Z, Hua N, Godber JS (2001) Antioxidant activity of tocopherols, tocotrienols $\quad \& \quad \gamma$-oryzanol components from rice bran against cholesterol oxidation accelerated by 2,2'-Azo-bis methylpropionamidin) 
Dihydrochloride. J Agric Food Chem, 49: 2077-2081.

[5] Yoon SH, Kim SK (1994) Oxidative stability of high fatty acid rice bran oil at different stages of refining. JAOCS , 75: 227-229.

[6] Bingham SA, Day NE, Luben R, Ferrari P, Slimani N, et al. (2003) Dietary fiber in food \& protection against colorectal cancer in the European Prospective Investigation into Cancer \& Nutrition (EPIC): an observational study. Lancet, 361: 1496-1501.

[7] Bonithon-Kopp C, Kronborg O, Giacosa A, Ulrich R, Jean F, et al. (2000) Calcium and fibre supplementation in prevention of colorectal adenoma recurrence: a randomised intervention trial. Lancet, 356: 1300-1306.

[8] Takeshita Yasuhiko, Iwata Fumio (1988) Recent technical advances in rice bran oil processing (II About refining process). Transactions of the Kokushikan Univ., Faculty of Engineering, 21: 118-124.

[9] Van Hoed V, Depaemelaere G, Villa Ayala J, Santiwattana P, VerhéR, De, et al. (2006) Influence of chemical refining on the major \& minor components of rice bran oil. JAOCS, 83: 315-321.
[10]Zhao W, Shishikura A, Fujimoto K, Ara K, Saito S (1987) Fractional extraction of rice bran oil with supercritical $\mathrm{CO} 2$. JpnAgricBiol Chem, 51: 17731777.

[11]De Deckere EAM, Korver O. (1996)Minor constituents of rice brain oil as functional foods. Nutr Rev, 54: S120-S126.

[12]Faivre J, Bonithon-Kopp C (1999) Chemoprevention of colorectal cancer. Recent Results Cancer Res, 151: 122-133.

[13]Ramsay M E, Hsu JT, Novak RA, Reightler WJ (1991)Processing rice bran by supercritical fluid extraction. Food Technol, 45: 98104.29.

[14] Sreenarayanan VV, Chattopadhyay PK (1986) Rice bran stabilization by dielectric heating. J Food Proc Preserv, 10: 89-98.

[15] Halden K, de Alwis AAP, Fryer PJ (1990) Changes in the electrical conductivity of foods during ohmic heating. Int $\mathrm{J}$ Food Sci Technol, 25: 9-25.

[16]Lebesi DM, Tzia C (2009) Effect of the addition of dietary fiber \& edible cereal bran sources on the baking \& sensory characteristics 
of cupcakes. Food Bioprocess

Technol, 4: 710-722.

[17]McCaskill DR, Zhang F (1999)

Use of rice bran oil in foods. Food

Technol, 53: 50-54.59.

[18] Miliauskas, G., P.R. and V. TA. (2004) Screening of radical scavenging activity of some medical and aromatic plant extracts. Food Chem., 84: 231-237

[19] Nakatani N, Tachibana Y, Kikuzaki H (2001) Establishment of a model substrate oil for antioxidant activity assessment by oil stability index method. JAOCS, 78: 19-23.

[20]Y. Gong, H. Yao (2001) "Purification and identification of $\gamma$-oryzanol from rice bran", $\mathrm{J}$. Chinese Cereals and Oils Assoc, 16: $30-34$

[21] Singh, N. Yadav, P.K. Mishra, S. Sheikh (2013), "Utilization of rice bran for development of chapatti and its glycemic response in NIDDM patients", Int. Res J Pharm. App Sci.,3: 244-248

[22]K.A. Moldenhauer, E.T. Champagne, D.R. Mc Caskill, H. Guraya,(2003) Functional products from rice, In: G. Mazza (Ed) Functional Foods: Technomic Publishing Co., Inc. Lancaster, Base, pp. 71-89
[23] S. Bhosale, D. Vijayalakshami, R. Chandru and H.B. Shivaleela(2015), "Processing of rice bran and utilization in food products", Indian Journal of Nutrition and Dietetics, 52: 253265

[24]Luh BS, Liu YK (1980) Rice flours in baking. Juliano B O, ed., 470-485.56.

[25] Sekhon KS, Dhillon SS, Singh N, Singh B (1997) Functional suitability of commercially milled rice bran in India for use in different food products. Plant foods for human nutrition, 50: 127-140.

[26]E.P. Ryan, A.L. Heuberger, T.L. Weir, B. Barnett, C.D. Broeckling, J.E. Prenni (2011)“ Rice bran fermented with Saccharomyces boulardii generates novel metabolite profiles with bioactivity", J. Agric. Food. Chem, 59: 1862-18D.

[27]Saikia, S.C. Deka (2011) "Cereals: from staple food to nutraceuticals- A Review", International Food Research J, 18: 21-30

[28]X.Q. Zha, J.P. Luo, L. Zhang, J. Hao (2009), “Antioxidant properties of different polysaccharides extracted with 
water and sodium hydroxide from rice bran", Food Science and Biotechnology, 18: 449-455

[29] Shugo M (1979) Anti-dandruff and anti-itching shampoo. Japanese Patent, 79: 36306.

[30] T.A. Wilson, L.M. Ausman, C.W. Lawton, M. Hegsted, R.J. Nicolosi (2000) "Comparative cholesterol lowering properties of vegetable oils: beyond fatty acids", Journal of the American College of Nutrition, 19: 601-607

[31] R.D. Verschoyle, P. Greaves, H. Cai, R.E. Edwards, W.P. Steward et al. (2007) "Evaluation of the cancer chemopreventive efficacy of rice bran in genetic mouse models of breast, prostate and intestinal carcinogenesis", Br. J. Cancer, 96: 248-254

[32] D.S. Barnes, N.K. Clapp, D.A. Scott, D.L. Oberst, S.G. Berry (1983). "Effects of wheat, rice, corn, and soybean bran on 1, 2-dimethylhydrazine-induced large bowel tumorigenesis in F344 rats", Nutrition and Cancer, 5: $1-9$

[33]A.A. Qureshi, S.A. Sami, F.A. Khan et al. (2002) "Effects of stabilized rice bran, its soluble \&fiber fractions on blood glucose levels \& serum lipid parameters in humans with diabetes mellitus types I \& II", J. Nutr. Biochem. 13: $175-187$

[34]Lichtenstein AH, Ausman LM, Carrasco W, Gualtieri LJ, Jenner JL, et al. (1994) Rice bran oil consumption $\&$ plasma lipid levels in moderately hypercholesterolemic humans. Arterioscler Thromb, 14: 549-556.

[35] Hegsted M, Windhauser MM (1993) Reducing human heart disease risk with rice bran. Louisiana Agriculture, 36: 22-23.

[36] Noboru $K$ \& Yusho $T$ (1970) Oryzanol Containing Cosmetics. Japanese Patent 70: 32078. 109.

[37]R.R. Eitenmiller (1997) "Vitamin E Content of fats and oils: nutritional implications", Food Technology, 51: 78-81

[38]Fujiwara, S. Noumi, I. Suqimoto, N. Awata et al (1982) "Mass fragmentographic determination of ferulic acid in plasma after oral administration of gammaoryzanol", Chem. Parm. Bull, 30: 973-979. 